\title{
Surgery or conservative management for Achilles tendon rupture?
}

\author{
Patients need better evidence on functional outcomes, including a return to sport
}

\author{
Nicola Maffulli professor, chair, and head of service ${ }^{12}{ }^{3}$, Giuseppe M Peretti professor and chair ${ }^{4}$
}

${ }^{1}$ Department of Musculoskeletal Disorders, Faculty of Medicine and Surgery, University of Salerno, Salerno, Italy; ${ }^{2}$ Queen Mary University of London, Barts and the London School of Medicine and Dentistry, Centre for Sports and Exercise Medicine, Mile End Hospital, London E1 4DG, UK; ${ }^{3}$ Institute of Science and Technology in Medicine, Keele University School of Medicine, Stoke on Trent, UK; ${ }^{4}$ IRCCS Istituto Ortopedico Galeazzi, Milan, Italy

\begin{abstract}
Acute ruptures of the Achilles tendon are common and can lead to major functional limitations, with noticeable loss of strength and endurance. ${ }^{1}$ Many such patients fail to resume sporting activities in the short term, and the injury produces ongoing problems even after 10 years. ${ }^{2}$ Modern management aims to promptly maximise function and minimise complications. Much of recent research has tried to determine the optimal methods of either surgical or non-surgical treatment using a randomised controlled trial study design, with the primary outcome in most of such studies being the prevention of re-ruptures. In a linked systematic review and meta-analysis, Ochen and colleagues (doi:10.1136/bmj.k5120) carefully analysed 29 studies in this specialty, including 19 observational and 10 randomised controlled trials. ${ }^{3}$
\end{abstract}

This rigorous work is to be commended. Ochen and colleagues' investigation emphasises the importance of including high quality observational studies as well as randomised controlled trials, and the results are sound: compared with non-operative management, surgery statistically significantly reduced the risk of re-rupture, but significantly increased the risk of other complications. $^{3}$

Is this the end for surgical management? Well, not quite. A few interesting facts should be noted when interpreting these findings: the risk of re-rupture was low after both surgery (2.3\%) and conservative management (3.9\%). The rate of postoperative complication after surgery was equally low (4.9\%), and the differences between surgical and non-operative management were small for both outcomes. Indeed, the differences may have been statistically significant, but the clinical relevance is questionable. $^{3}$

Several techniques are available for percutaneous or minimally invasive repair of acute tears of the Achilles tendon. Comparative studies ${ }^{4-6}$ and a systematic review ${ }^{7}$ show that minimally invasive and open surgery of the Achilles tendon produce equivalent results. Minimally invasive and percutaneous surgery carry a greater risk of iatrogenic injury to the sural nerve $^{1}$ : however, the functional impairment induced by such a complication is minor and does not compromise the function of the foot and ankle, and the leg. Novel percutaneous repair techniques have been developed to minimise the risk of sural nerve injury. ${ }^{8}$

\section{Measuring outcomes that matter}

As Ochen and colleagues show, the difference in re-rupture rate between operative and non-operative management is small and not clinically relevant when examined at population level. ${ }^{2}$ However, other outcomes are equally important to patients, and other studies have shown that patients treated conservatively take longer to return to sport, are less strong, and have less confidence in their Achilles tendon. ${ }^{56}$ Future studies should be powered to evaluate recovery of strength and endurance in the gastro-soleus complex and return to high level physical activities, as well as other patient centred functional outcomes. These studies will require greater numbers of participants, followed up for longer than in previous studies.

Many surgeons in the United Kingdom manage acute rupture of Achilles tendon conservatively. This has resulted in a growing cohort of people with a healed Achilles tendon that is elongated, altering the relation between the tendon and the gastro-soleus muscle complex. ${ }^{9}$ These individuals develop a more acute Achilles tendon resting angle, ${ }^{9}$ and they are not able to push off properlywhen walking, ascending and descending stairs, and running. They have problems similar to patients with a chronic Achilles tendon rupture. Corrective operations have been described, ${ }^{10}$ but reconstructive surgery is more technically demanding than primary repair procedures - recovery is long and often less optimal than following primary surgical repair. ${ }^{10}$ The most common functional evaluation score, the Achilles Tendon Total Rupture Score, ${ }^{11}$ is generally lower after non-operative management than surgical management. ${ }^{23}$ Although the difference is not statistically significant, ${ }^{23}$ it might still have a noticeable effect on patients' confidence and return to activity. 
In the absence of better evidence on the long term outcomes that matter most to patients, this debate is likely to continue. Non-operative management of Achilles tendon rupture is apparently cheaper and avoids surgical complications. However, less invasive surgical repair techniques performed under local anaesthesia in outpatients can be safe and effective. ${ }^{12}$ A recent cost effectiveness analysis showed a 57\% likelihood for surgical treatment to be cost effective at a willingness to pay per quality adjusted life year threshold of $€ 50000$ ( $£ 44900$; $\$ 56600$ ). ${ }^{13}$

A personalised approach incorporating fully informed shared decision making remains essential for the management of acute ruptures of the largest and strongest tendon of the human body. ${ }^{14}$

Competing interests: The BMJ has judged that there are no disqualifying financial ties to commercial companies. The authors declare the following other interests: none.

Provenance and peer review: Commissioned; not peer reviewed.

1 Maffulli N. Rupture of the Achilles tendon. J Bone Joint Surg Am 1999:81:1019-36. 10.2106/00004623-199907000-00017 10428136

2 Olsson N, Nilsson-Helander K, Karlsson J, etal . Major functional deficits persist 2 years after acute Achilles tendon rupture. Knee Surg Sports Traumatol Arthrosc 2011;19:1385-93. 10.1007/s00167-011-1511-3 21533539

3 Ochen $\mathrm{Y}$, Beks RB, van Heijl M, etal . Operative treatment versus nonoperative treatment of Achilles tendon ruptures: systematic review and meta-analysis. BMJ 2018:364:k5120.

4 Baumfeld D, Baumfeld T, Spiezia F, Nery C, Zambelli R, Maffulli N. Isokinetic functional outcomes of open versus percutaneous repair following Achilles tendon tears. Foot Ankle Surg 2018. 10.1016/j.fas.2018.03.003
5 Ebinesan AD, Sarai BS, Walley GD, Maffulli N. Conservative, open or percutaneous repair for acute rupture of the Achilles tendon. Disabil Rehabil 2008;30:1721-5. 10.1080/09638280701786815 18608405

6 Miller D, Waterston S, Reaper J, Barrass V, Maffulli N. Conservative management, percutaneous or open repair of acute Achilles tendon rupture: a retrospective study. Scott Med J 2005;50:160-5. 10.1177/003693300505000408 16374980

7 Del Buono A, Volpin A, Maffulli N. Minimally invasive versus open surgery for acute Achilles tendon rupture: a systematic review. Br Med Bull 2014;109:45-54. $10.1093 / \mathrm{bmb} / \mathrm{dt} 02924126569$

8 Zappia M, Berritto D, Oliva F, Maffulli N. High resolution real time ultrasonography of the sural nerve after percutaneous repair of the Achilles tendon. Foot Ankle Surg 2018;24:342-6. 10.1016/j.fas.2017.03.006 29409243

9 Carmont MR, Grävare Silbernagel K, Brorsson A, Olsson N, Maffulli N, Karlsson J. The Achilles tendon resting angle as an indirect measure of Achilles tendon length following rupture, repair, and rehabilitation. Asia Pac J Sports Med Arthrosc Rehabil Technol 2015;2:49-55. 10.1016/j.asmart.2014.12.002 29264240

10 Maffulli N, Spiezia F, Longo UG, Denaro V. Z-shortening of healed, elongated Achilles tendon rupture. Int Orthop 2012;36:2087-93. 10.1007/s00264-012-1602-x 22782374

11 Nilsson-Helander K, Thomeé R, Silbernagel KG, etal . The Achilles tendon Total Rupture Score (ATRS): development and validation. Am J Sports Med 2007;35:421-6. 10.1177/0363546506294856 17158277

12 Maffulli G, Buono AD, Richards P, Oliva F, Maffulli N. Conservative, minimally invasive and open surgical repair for management of acute ruptures of the Achilles tendon: a clinical and functional retrospective study. Muscles Ligaments Tendons J 2017;7:46-52. 10.11138/mlt $/ 2017.7 .1 .04628717611$

13 Westin O, Svensson M, Nilsson Helander K, etal . Cost-effectiveness analysis of surgica versus non-surgical management of acute Achilles tendon ruptures. Knee Surg Sports Traumatol Arthrosc 2018;26:3074-82. 10.1007/s00167-018-4953-z 29696317

14 Oliva F, Rugiero C, Giai Via A, etal . Achilles tendon ruptures guidelines. Muscles Ligaments Tendons J 2018;8:310-363.

Published by the BMJ Publishing Group Limited. For permission to use (where not already granted under a licence) please go to http://group.bmj.com/group/rights-licensing/ permissions 